\title{
$1^{0}$ Encontro de Química de Alimentos
}

\author{
SOCIEDADE PORTUGUESA DE QUÍMICA / GRUPO DE QUÍMICA ALIMENTAR \\ Com o apoio da União Europeia (Programa Flair)
}

Comunicaços convidadas (parte II)

Escola Superior Agrária de Santarém

SANTAREM - 19 a 22 de Dezembro de 1993

\section{Aplicação de Técnicas de Análise Multivarietal no Reconhecimento de Vinhos Elementares}

\author{
A.M.P. VASCONCELOS*
}

A caracterização enológica assenta, principalmente, na análise sensorial. 0 carácter subjectivo da prova é, por si só, um estímulo grande na procura de novos métodos capazes de identificar $e$ reconhecer vinhos, os quais, sendo baseados em determinações químicas serão, necessariamente, mais objectivos.

As técnicas de análise de perfil têm já sido utilizadas na caracterização enológica, recorrendo quer aos resultados das análises elementares [1-4] quer aos aminoácidos totais [5] quer aos componentes voláteis [6,7]. No nosso trabalho foram utilizados os aminoácidos livres. Estes compostos existem no fruto maduro de Vitis vinifera onde são acumulados principalmente durante o processo de maturação.

Ao estudar 8 vinhos elementares num período de sete anos conseguimos demonstrar a existência de uma correlação entre o perfil de aminoácidos e a variedade inicial de Vitis vinifera.

Os aminoácidos foram estudados por cromatografia gás-líquido de alta resolução após derivatização para obtenção dos ésteres isopropílicos $\mathrm{N}$-heptafluorbutíricos. A aplicação da mesma técnica de cluster hierárquico, quando aplicada aos D-aminoácidos existentes num conjunto de vinhos brancos estudados durante dez anos, permitiu obter uma separação que está de acordo com a tecnologia utilizada durante o processamento.

\section{INTRODUÇÃO}

A crescente procura de parâmetros de qualidade capazes de permitir definir qualidade nos alimentos, tem vindo a provocar uma constante procura de métodos para essa caracterização. Os vinhos ocupam em Portugal uma área de produção significativa pelo que 0 interesse manifestado na caracterização enológica se reveste de uma componente nacional e científica. 0 vinho pode ser considerado como um reflexo da uva que Ihe dá origem. A qualidade da uva influencia significativamente a qualidade do produto final. 0 produto final Vinho é, no entanto, muito mais do que uva esmagada, pois por detrás disto tudo surge a fermentação alcoólica cuja complexidade de fenómenos que a acompanham permite 0 desenvolvimento de um produto final, quase mítico, o qual tem sido descrito incessantemente ao longo da história de formas várias, e do qual se pode quase dizer que 'pode-se odiar ou amar, mas nunca ficar indiferente", ou tal como disse Pasteur "II y a plus de philosophie dans une bouteille de vin que dans tous les livres".

Por esta quase impossivel indiferença que o homem tem ao longo dos anos demostrado pelo vinho, a sua composição tem sido objecto de largos estudos, discussões e publicações. A forma até hoje mais capaz de definir e qualificar um vinho como uma obra de arte é a prova organoléptica. A análise sensorial não é contudo fácil, quase que se pode dizer que é uma vocação; no entanto 0 provador tem a sua subjectividade e este facto tem levado à procura de formas alternativas de tentar definir o quase indefinivel parâmetro que é a qualidade. Os resultados obtidos têm permitido, com a ajuda da análise química e microbiológica, dizer, com segurança, se um produto é ou não Vinho relacionando-0 com a sua região de origem [4]e se está ou não em condicões de ser comercializado. Em resumo, se obedece aos parâmetros legais [3], ou ainda para dividir regiões vínicolas em subzonas de aptidão agrícola [8]. Por outro lado também oS avanços conseguidos têm permitido concordância quanto ao reconhecimento que, dada a complexidade do produto, um só parâmetro nunca será suficiente para caracterizar o produto e nem sequer para o "legalizar". Exemplo disso é 0 reconhecimento hoje de que o chamado "Teste da Prolina" [9] durante anos considerado como capaz de definir vinho de Vitis Vinifera de vinho com adulterações já hoje foi reconhecido como não sendo válido. Este exemplo fez surgir a necessidade de se olhar não para um parâmetro mas para um conjunto de parâmetros capazes de definir um perfil característico. 0 Objectivo deste trabalho foi definir se 0 perfil de aminoácidos era caracteristico do vinho inicial. A escolha dos aminoácidos para este tipo de abordagem residiu no facto de eles estarem presentes no vinho desde a uva até ao final da frementação, terem papel activo durante a frementação, e terem ainda papel activo na uva durante todo o processo de maturação. São pois compostos que 
"acompanham" todo o processo desde 0 início. Os vinhos escolhidos foram vinhos elementares, ou seja vinhos de casta pura provenientes da mesma vinha. Pretendeu-se uniformizar e dar um assento tónico na casta, eliminando as variáveis solo e clima. As castas escoIhidas podem ser consideradas na região do Alentejo com as castas eleitas, ou seja, se nada ocorrer de errado durante 0 processo dariam vinhos de qualidade.

\section{MATERIAL E MÉTODOS}

Amostras 0 s vinhos utilizados foram vinificados na adega experimental da Universidade de Évora tendo os vinhos brancos sido vinificados de bica aberta e os tintos de curtimenta [10]. Os vinhos brancos analizados após 1983 e que fazem parte do estudo dos aminoácidos $D$ foram vinificados no frio [11]. As castas escolhidas estavam implantadas inicialmente no campo de ensaio da Herdade do Esporão em Reguengos de Monsaraz e mais tarde no campo experimental da Universidade de Évora na Herdade da Mitra. Todos os vinhos são engarrafados após a fermentação alcoólica e maloláctica. 0 tempo em garrafa depende apenas do ano de colheita.

Isolamento e análise dos aminoácidos 0s aminoácidos foram isolados dos vinhos por cromatografia de troca-iónica após deproteinização, tendo sido analizados por cromatografia gás-líquido sob a forma de ésteres isopropílicos N-heptafluorbutíricos [10] ou N-pentafluorbutíri$\cos$ [12], em colunas capilares respectivamente revestidas por OV-101 e Chirasil-val ${ }^{\circledR}$.

Análise estatística A análise de componente principal, a análise discriminante e a análise de projecção em estrela foram realizadas utilizando sub-rotinas do programa STATGRAPHICS, a análise de cluster foi realizada utilizando o programa CLUE [10].

Os resultados obtidos na análise dos aminoácidos livres das oito castas estudadas analizadas durante os sete anos de estudo encontram-se inscritos na Tabela 1 [13]. É fácil predizer que qualquer tentativa de retirar informação importante deste amálgama de números seria trabalho quase impossivel, ficando ainda por saber se seria de alguma forma útil.

A análise de perfil é ideal para desconvolucionar estes dados retirando-Ihes a informação útil, fazendo-a sobressair do conjunto de dados obtidos.

Para este tipo de análise cada vinho foi considerado como objecto, definido por 22 aminoácidos os quais constituem 0 vector que define cada objecto. A análise de componente principal ao ser aplicada a este conjunto de objectos assim definidos permitiu seleccionar 13 variáveis (Fig.1A) Alanina (Ala), Treonina
(Thr), Serina (Ser), Leucina (Leu), Cisteína (Cys), Aspártico/Asparagina (Asx), Hidroxiprolina (Hyp), Metionina (Met), Glutâmica/Glutamina (Glx), Fenilalanina (Phe), Lisina (Lys), Isoleucina (IIe) e Tirosina (Tyr) cujos pesos nos dois primeiros componentes principais explicam $68 \%$ da variabilidade total.

Considerando apenas estes aminoácidos na análise de componente principal verificou-se que os vinhos Brancos e Tintos são completamente separados, havendo uma tendência para 0 agrupamento entre as castas Roupeiro e Rabo de Ovelha (brancas) e Moreto e Trincadeira (Tintas) (Fig. 1B). Este resultado
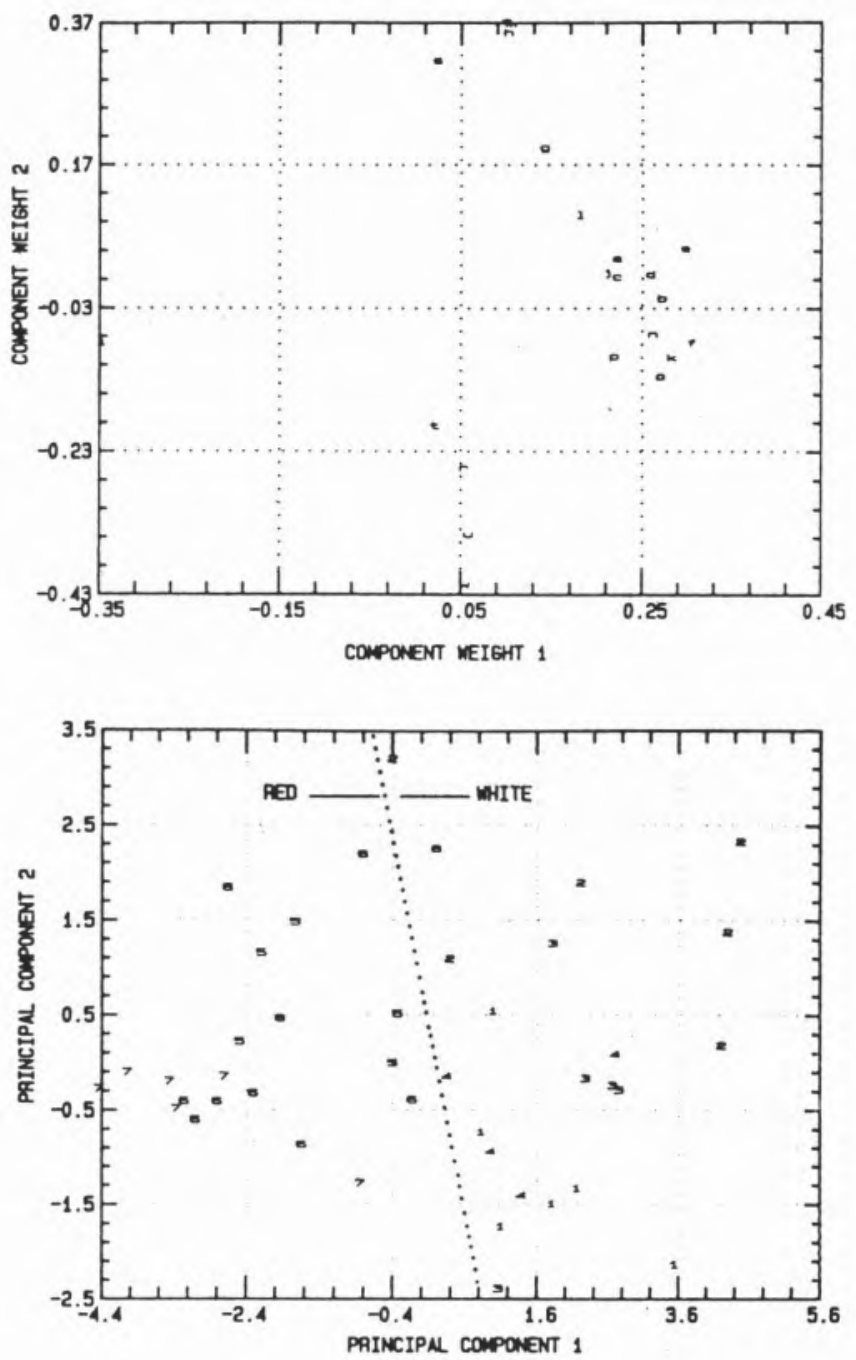

Figura 1- Análise de componente principal.

Fig. 1 A - A projecção dos pesos dos componentes do $1^{\circ}$ e $2^{\circ}$ componentes principais. a-Alanina; b-Glicina, c-Valina; d-Treonina; e -Serina; $f$-Leucina; g-Isoleucina; $h$ - $\gamma$-Aminobutírico; $i$ - Prolina;

j- Cisteina; k-Aspártico/asparagina; I - Hidroxiprolina; m - Metionina; $n$ - Glutamico/glutamina;

0 - Fenilalanina; p - Lisina; q - Tirosina; r - Histidina;

s- Ornitina; $\mathrm{t}$ - Arginina; u-Sarcosina; w-Aminobutirico.
Fig. 1B-Projecção do $1^{\circ}$ versus $02^{\circ}$ componentes principais com as variáveis reduzidas pela análise anterior.

1-Roupeiro; 2-Manteúdo: 3-Tamarez; 4-Rabo de Ovelha; 5-Moreto; 6-Trincadeira; 7 - Periquita; 8 - Aragonez. 
Tabela I Percentagens Normalizadas da Composição em Aminoácidos Livres de Vinhos Elementares de Variedades de $V$. vinifera. R- Roupeiro; Ro- Rabo de Ovelha; T-Tamarez; M- Manteúdo; A-Aragonez; Mo-Moreto; P-Periquita; Tr-Trincadeira.

Aminoácidos \% ${ }^{\mathrm{a}, \mathrm{b}, \mathrm{c}}$

\begin{tabular}{|c|c|c|c|c|c|c|c|c|c|c|c|c|c|c|c|c|c|c|c|c|c|c|}
\hline ple & $\mathrm{Ala}$ & Gly & Abu & Sar & Val & Thr & Ser & Leu & Ile & Gaba & Pro & Cys & Asx & Hyp & Met & Glx & Phe & Orn & Lys & Tyr & His & Arg \\
\hline$\overline{R 77}$ & 6.5 & 3.8 & & & 2.3 & 2.8 & 3.8 & 5.1 & 5.1 & 0.4 & 51.2 & 1.5 & 7.5 & 1.9 & 2.8 & 5.9 & 3.1 & & 5.1 & & 0.5 & 0.6 \\
\hline R79 & 6.5 & 3.8 & & & 2.3 & 2.8 & 4.0 & 7.8 & 0.2 & 0.2 & 32.5 & 0.8 & 7.6 & 2.0 & 1.1 & 4.8 & 4.0 & & 4.8 & & 1.3 & 1.6 \\
\hline R80 & 5.0 & 4.4 & & & 4.2 & 1.6 & 6.2 & 10.3 & & 2.2 & 28.3 & 2.4 & 9.5 & 2.2 & 2.2 & 9.7 & 6.8 & & 0.5 & 1.1 & & \\
\hline R81 & 7.4 & 4.0 & & & 3.4 & 3.0 & 4.7 & 8.4 & & 3.0 & 39.5 & 6.8 & 7.6 & 1.8 & 1.6 & 6.5 & 5.0 & & 6.0 & 0.3 & & \\
\hline R82 & 7.2 & 3.7 & & & 1.4 & 2.2 & 4.2 & 5.5 & & 1.5 & 47.7 & 7.3 & 4.1 & 1.8 & 1.0 & 6.2 & 2.3 & & 2.4 & 1.2 & & \\
\hline R83 & 6.3 & 3.9 & & & 2.7 & 3.0 & 4.6 & 7.4 & & & 39.8 & 3.8 & 7.5 & 1.9 & 1.7 & 6.6 & 4.2 & & 3.8 & & & \\
\hline mean & 6.3 & 3.9 & & & 2.7 & 3.1 & 4.6 & 7.4 & & 1.2 & 39.8 & 3.8 & 7.3 & 1.9 & 1.7 & 6.6 & 4.2 & & 3.8 & & & \\
\hline $\mathrm{SD}^{6}$ & 14.5 & 6.4 & & & 35.8 & 3.1 & 18.8 & 25.9 & & 72.6 & 21.8 & 72.7 & 24.0 & 7.7 & 39.2 & 24.8 & 37.0 & & 53.6 & & & \\
\hline med $^{e}$ & 6.4 & 3.9 & & & 2.5 & 2.9 & 4.4 & 7.6 & & 1.0 & 39.7 & 3.1 & 7.6 & 1.9 & 1.7 & 6.4 & 4.1 & & 4.3 & & & \\
\hline Ro77 & 7.0 & 4.6 & 5.2 & 0.6 & 4.5 & 3.7 & 4.2 & 6.1 & 1.2 & 0.9 & 43.5 & 5.0 & 5.6 & 0.8 & 0.9 & 5.0 & 3.6 & & 4.0 & & & \\
\hline Ro78 & 8.2 & 2.7 & & & 4.7 & 2.6 & 3.0 & 5.7 & 2.7 & 2.2 & 36.8 & 2.6 & 5.5 & 0.4 & 1.6 & 3.3 & 2.1 & 11.1 & 5.0 & 0.4 & 1.2 & \\
\hline Ro81 & 12.5 & 5.6 & 2.5 & & 9.7 & 1.3 & 2.5 & 9.4 & & & 31.3 & 4.1 & 5.6 & 0.8 & 1.5 & 5.9 & 4.4 & Q.7 & 10.9 & & 2.3 & \\
\hline Ro82 & 7.4 & 6.0 & 3.8 & 0.6 & 20 & 4.0 & 6.0 & 7.0 & 4.5 & 1.5 & 29.0 & 4.2 & 5.7 & 1.1 & 2.1 & 6.4 & 5.6 & 0.7 & 8.7 & & & \\
\hline mean & 8.8 & 47 & 3.8 & & 5.2 & 2.9 & 3.9 & 7.1 & 2.8 & 1.5 & 35.2 & 3.9 & 5.6 & 0.8 & 1.5 & 5.2 & 3.9 & 4.2 & 7.2 & & & \\
\hline & 28.9 & 31.2 & 28.7 & & 61.7 & 42.2 & 39.6 & 23.5 & 48.1 & 34.6 & 18.3 & 25.2 & 1.4 & 37.1 & 32.3 & 26.5 & 37.4 & & 44.9 & & & \\
\hline med & 7.8 & 5.1 & 3.8 & & 4.6 & 3.2 & 3.6 & 6.6 & 2.8 & 1.5 & 36.1 & 12 & 5.6 & 0.8 & 1.6 & 5.5 & 4.0 & 0.7 & 6.9 & & & \\
\hline T79 & 14.5 & 7.9 & & & 3.5 & 5.6 & 6.1 & 8.4 & 1.7 & & 18.9 & 20 & 6.1 & 1.5 & 2.6 & 2.9 & 3.2 & & 3.9 & 3.5 & & \\
\hline T80 & 8.2 & 4.6 & & & 6.3 & 3.6 & 4.5 & 7.1 & 3.5 & & 28.6 & 43 & 6.7 & 0.9 & 1.6 & 5.9 & 3.5 & 1.1 & 5.9 & 1.1 & & \\
\hline T81 & 12.0 & 7.5 & & & 6.7 & 1.5 & 2.4 & 12.6 & 1.2 & & 360 & 0.4 & 60 & 1.9 & 0.9 & 1.7 & 7.2 & & & & & \\
\hline T82 & 7.7 & 5.7 & & & 2.2 & 2.8 & 6.5 & 5.2 & 1.6 & & 30.4 & 30 & 4.7 & 2.6 & 4.1 & 3.0 & 2.2 & & 13.8 & 1.8 & & \\
\hline$T 83$ & 10.9 & 8.6 & & & 5.9 & 4.2 & 4.6 & 8.1 & 1.7 & & 14.9 & 48 & 6.7 & 2.3 & 3.7 & 4.4 & 4.1 & & 6.0 & & & \\
\hline Fean & 10.7 & 6.9 & & & 4.9 & 3.5 & 4.8 & 8.3 & 1.9 & & 256 & 3.1 & 6.0 & 1.8 & 26 & 3.6 & 40 & & 7.4 & 21 & & \\
\hline $\mathrm{SD}$ & 26.3 & 24.1 & & & 39.9 & 43.3 & 33.6 & 32.8 & 46.2 & & 34.3 & 55.0 & 13.5 & 36.7 & 46.8 & 45.0 & 46.9 & & 51.2 & 17.2 & & \\
\hline Lmed & 10.9 & 7.5 & & & 5.9 & 3.6 & 4.6 & 8.1 & 1.7 & & 28.6 & 3.0 & 6.1 & 1.8 & 2.6 & 3.0 & 3.5 & & 60 & 18 & & \\
\hline M77 & 5.5 & 2.6 & & & 3.0 & 2.6 & 3.6 & 4.2 & 20 & 38 & 42.1 & 4.3 & 4.1 & 1.6 & 2.9 & 4.6 & 2.2 & 2.4 & 3.1 & 4.2 & & \\
\hline M78 & 6.9 & 2.5 & & & 4.7 & 2.0 & 0.7 & 5.9 & 28 & 2.3 & 31.2 & 3.0 & 0.8 & 0.3 & 3.1 & 3.5 & 2.7 & 8.2 & 0.6 & 15.8 & & \\
\hline M79 & 10.3 & 6.1 & & & 4.6 & 48 & 7.5 & 8.6 & 3.1 & 6.5 & 5.0 & 5.3 & 8.5 & 24 & 3.6 & 5.5 & 4.1 & & 7.5 & 8.6 & & \\
\hline M81 & 7.9 & 7.9 & & & 7.8 & 5.4 & 7.2 & 9.5 & 3.7 & 3.4 & 2.4 & 5.2 & 5.6 & 15.2 & 3.1 & 5.7 & 5.0 & 6.9 & 2.3 & 1.5 & & \\
\hline M82 & 8.5 & 9.2 & & & 4.1 & 4.9 & 10.7 & 7.4 & 3.5 & 36 & 1.9 & 3.6 & 6.9 & 3.4 & 5.9 & 5.1 & 4.6 & 4.0 & 5.7 & 6.9 & & \\
\hline M83 & 6.9 & 4.8 & & & 3.1 & 3.5 & 6.3 & 7.8 & 39 & 3.3 & 31.5 & 3.1 & 6.5 & 1.0 & $4 . !$ & 6.1 & 3.9 & & 5.9 & 2.0 & & \\
\hline mean & 7.7 & 5.5 & & & 4.6 & 3.9 & 6.0 & 7.2 & 3.2 & 3.8 & 19.0 & 4.1 & 5.4 & 4.0 & 3.8 & 5.1 & 3.8 & 5.4 & 42 & 7.7 & & \\
\hline SD & 21.4 & 49.7 & & & 38.4 & 35.7 & 57.6 & 26.5 & 22.0 & 37.0 & 94.1 & 24.8 & 49.7 & 140.5 & 29.7 & 18.3 & 20.0 & 42.7 & 62.1 & 63.7 & & \\
\hline$[\mathrm{med}$ & 7.4 & 5.5 & & & 4.4 & 4.2 & 6.8 & 7.6 & 33 & 35 & 18.1 & 4.0 & 6.1 & 20 & 2.4 & 5.3 & 40 & 5.5 & 44 & 78 & & \\
\hline A78 & 7.1 & 2.1 & & & 1.8 & 0.9 & 1.4 & 1.6 & 1.2 & 8.0 & 40.8 & 0.9 & 3.0 & 0.04 & 3.0 & 3.2 & 1.8 & 14.4 & 1.0 & 1.4 & & \\
\hline A81 & 7.0 & 2.3 & & & 3.7 & 1.9 & 28 & 5.2 & 27 & 2.1 & 46.9 & 2.4 & 4.1 & 0.2 & 4.6 & 3.4 & 2.4 & 0.9 & 3.4 & 7.8 & & \\
\hline A82 & 2.4 & 1.8 & & & 1.6 & 1.0 & 1.2 & 1.6 & 0.9 & 1.3 & 68.1 & 1.6 & 2.2 & 0.5 & 5.9 & 1.5 & 0.4 & 1.7 & 0.8 & 0.2 & & \\
\hline mean & 5.5 & 2.1 & & & 24 & 1.3 & 1.8 & 2.8 & 1.6 & 3.8 & 51.9 & 1.6 & 3.1 & 0.3 & 4.5 & 2.7 & 1.5 & 5.7 & 1.8 & 3.1 & & \\
\hline SD & 48.8 & 12.2 & & & 48.9 & 43.4 & 48.4 & 74.2 & 56.9 & 96.3 & 27.8 & 45.9 & 30.8 & 103.0 & 32.5 & 36.1 & 66.9 & 132.2 & 80.1 & 130.3 & & \\
\hline med & 7.0 & 2.2 & & & 1.8 & 1.0 & 1.4 & 1.6 & 1.2 & 2.1 & 46.9 & 1.6 & 3.0 & 0.2 & 4.5 & 3.2 & 1.8 & 1.7 & 1.0 & 1.4 & & \\
\hline Mo78 & 4.7 & 1.6 & & & 2.8 & 0.6 & 0.7 & 2.4 & 1.8 & 0.8 & 70.5 & 3.0 & 2.9 & 0.3 & 4.0 & 1.8 & 0.8 & & 123 & & & \\
\hline Mo79 & 7.1 & 2.3 & & & 6.1 & 2.4 & 24 & 5.6 & 3.8 & 2.6 & 51.7 & 2.6 & 4.1 & & 24 & 2.5 & 2.1 & & 22 & & & \\
\hline Mo81 & 3.4 & 2.2 & & & 27 & 1.2 & 1.3 & 2.3 & 1.1 & 2.1 & 73.1 & 5.1 & 28 & 0.1 & 1.1 & 0.7 & 0.7 & 0.5 & 0.8 & & & \\
\hline Mo82 & 4.5 & 1.6 & & & 2.5 & 1.4 & 1.8 & 23 & 1.2 & 2.1 & 64.5 & 3.5 & 2.2 & 0.6 & 5.2 & 2.6 & 0.9 & 1.7 & 1.3 & & & \\
\hline Mo83 & 9.0 & 6.8 & & & 4.8 & 2.3 & 26 & 4.4 & 2.8 & 4.9 & 45.8 & 2.5 & 4.2 & 0.2 & 2.2 & 3.8 & 1.5 & & 2.1 & & & \\
\hline thean & 5.7 & 2.9 & & & 3.8 & 1.6 & 1.7 & 3.4 & 2.1 & 2.5 & 61.1 & 3.3 & 3.2 & 0.3 & 3.0 & 2.3 & 1.2 & & 1.5 & & & \\
\hline SD & 35.3 & 67.9 & & & 37.7 & 43.2 & 39.7 & 40.0 & 47.9 & 53.6 & 17.4 & 28.3 & 24.5 & 62.3 & 35.5 & 44.6 & 44.1 & & 38.7 & & & \\
\hline med & 4.7 & 2.2 & & & 28 & 1.4 & 1.8 & 2.4 & 1.8 & 21 & 64.5 & 3.0 & 29 & 0.3 & 24 & 2.5 & 0.9 & & 1.3 & & & \\
\hline P77 & 4.5 & 3.2 & 1.4 & & 1.1 & 3.3 & 0.9 & 2.1 & 1.1 & 0.1 & 76.4 & & 1.6 & & 1.2 & 1.3 & 0.9 & & 0.9 & & & \\
\hline P78 & 14.4 & 4.0 & 0.6 & & 2.9 & 4.8 & 1.8 & 4.5 & 0.9 & 0.8 & 56.9 & 0.3 & 3.0 & & 0.5 & 2.9 & 0.3 & 1.0 & 0.4 & & & \\
\hline P79 & 3.7 & 1.9 & & & 1.7 & 1.1 & 1.1 & 2.5 & 0.4 & 0.2 & 83.3 & 0.3 & 0.9 & 0.4 & 1.1 & 0.4 & 0.9 & & & & & \\
\hline P81 & 3.9 & 1.5 & & & 2.2 & 0.7 & 0.9 & 2.4 & 0.5 & 0.4 & 82.1 & 0.1 & 2.5 & 0.8 & 0.5 & 1.2 & 0.2 & & & & & \\
\hline P82 & 1.8 & 1.2 & & & 0.4 & 0.3 & 0.3 & 0.4 & 0.1 & 0.08 & 93.0 & 0.2 & 0.7 & 0.1 & 0.2 & 0.5 & 0.3 & 9.2 & & & & \\
\hline P83 & 2.4 & 4.8 & & & 0.7 & 0.7 & 0.5 & 0.1 & 0.1 & 0.08 & 86.1 & 0.4 & 0.5 & 0.3 & 0.8 & 1.0 & 0.7 & 0.7 & & & & \\
\hline mean & 5.1 & 28 & & & 1.5 & 1.8 & 0.9 & 20 & 0.5 & 0.3 & 79.6 & 0.3 & 1.5 & 0.4 & 0.7 & 1.2 & 0.6 & & & & & \\
\hline SD & 83.0 & 75.0 & & & 57.7 & 91.0 & 52.1 & 73.0 & 73.0 & 91.8 & 14.2 & 43.8 & 61.0 & 73.6 & 49.2 & 71.3 & 53.2 & & & & & \\
\hline uned & 3.8 & 2.6 & & & 1.4 & 0.9 & 0.9 & 2.2 & 0.5 & 0.2 & 82.7 & 0.3 & 1.3 & 0.4 & 0.7 & 1.1 & 0.5 & & & & & \\
\hline $\operatorname{Tr} 77$ & 4.4 & 1.4 & & & 1.5 & 1.0 & 1.2 & 1.4 & 0.9 & 2.3 & 77.3 & & 3.5 & & 0.9 & 2.5 & 0.8 & & 0.8 & & & \\
\hline $\operatorname{Tr} 78$ & 8.9 & 2.1 & & & 2.7 & 1.9 & 1.7 & 1.9 & 1.2 & 11.1 & 58.3 & & 4.2 & & 0.7 & 4.3 & 1.1 & & 0.8 & & & \\
\hline Tr79 & 5.3 & 2.2 & & & 24 & 1.4 & 1.1 & 2.1 & 2.0 & 2.2 & 71.6 & & 4.8 & & 0.9 & 1.8 & 1.1 & & 1.0 & & & \\
\hline $\operatorname{Tr} 80$ & 6.0 & 1.1 & & & 2.9 & 1.7 & 1.7 & 3.0 & 1.5 & 20 & 50.5 & 1.6 & 3.3 & 0.9 & 6.3 & 3.4 & 2.1 & 5.1 & 2.2 & 4.5 & & \\
\hline Tr81 & 4.6 & 1.4 & & & 1.2 & 1.2 & 0.9 & 0.8 & 0.6 & 0.1 & 83.3 & 0.2 & 0.4 & 1.2 & 0.5 & 1.1 & 2.1 & & 0.6 & 0.1 & & \\
\hline Tr82 & 6.3 & 4.5 & & & 5.8 & 5.9 & 0.4 & 4.3 & 4.6 & 0.4 & 55.6 & 0.8 & 3.8 & 0.2 & 0.2 & 1.9 & 7.6 & & & 1.5 & & \\
\hline $\operatorname{Tr} 83$ & 3.2 & 1.9 & & & 1.6 & 1.5 & 0.5 & 1.2 & 0.7 & 0.2 & 80.1 & 0.3 & 28 & 0.2 & & 0.7 & 2.0 & & 1.0 & 0.7 & & \\
\hline mean & 5.5 & 2.1 & & & 2.6 & 2.1 & 1.1 & 2.1 & 1.6 & 2.6 & 68.1 & 0.7 & 3.3 & 0.6 & 1.6 & 2.3 & 2.4 & & 1.0 & 1.7 & & \\
\hline $\mathrm{S}$ & 30.4 & 50.5 & & & 55.7 & 76.6 & 44.8 & 53.0 & 78.0 & & 17.8 & 76.4 & 40.1 & 70.0 & 134.0 & 87.7 & 90.0 & & 49.2 & 99.4 & & \\
\hline med & 5.3 & 1.9 & & & 2.4 & 1.5 & 1.1 & 1.9 & 1.2 & 2.1 & 71.6 & 0.6 & 3.5 & 0.6 & 0.8 & 1.9 & 2.0 & & 0.8 & 1.1 & & \\
\hline
\end{tabular}


estava curiosamente de acordo com os resultados das provas organolépticas dos mesmos vinhos. A separação obtida nunca foi de $100 \%$ visto as variáveis apenas explicarem $68 \%$ da variabilidade total. 0 cluster foi feito pela métodos de agrupamento hierárquico tendo-se utilizado a distância euclidiana. Estes resultados parecem indicar que a separação e caracterização dos vinhos estudados será possivel. A separação dos dois grupos Tintos e Brancos mantém-se nítida quando baseada nos perfis de aminoácidos livres característicos dos mesmos.

0 método de componente principal para redução de variáveis foi aplicado a cada um dos vinhos durante os sete anos e obteve-se para cada casta/vinho 0 conjunto de aminoácidos característico do/a mesmo/a. A análise de cluster aplicada a este conjunto de vectores definidores de cada vinho permitiu obter 0 dendrograma da figura 2.

Igualmente se utilizou a análise discriminante para reafirmar a tendência verificada nas análises anteriores. A capacidade de reconhecimento de dois grupos brancos e tintos é total e 0 agrupamento dos vinhos em cada subgrupo de acordo com as castas também é total. A predição desta função é de $51 \%$ (Fig. 3A). A redução de variáveis, seleccionando aquelas que possuem maiores capacidades discriminatórias, permitiu-nos obter uma função discriminante com $81 \%$ de capacidade de discriminação com subgrupos bem formados. As classificações tiveram $78 \%$ de sucesso (Fig. 3B).

Figura 2 - Cluster Hierárquico de caracterização de Vinhos Elementares Alentejanos pela análise do perfi de aminoácidos livres. Mo-Moreto;

A-Aragonez: P-Periquita; Tr-Trincadeira: R- Roupeiro; O- Rabo de Ovelha; T-Tamarez; M-Manteúdo.
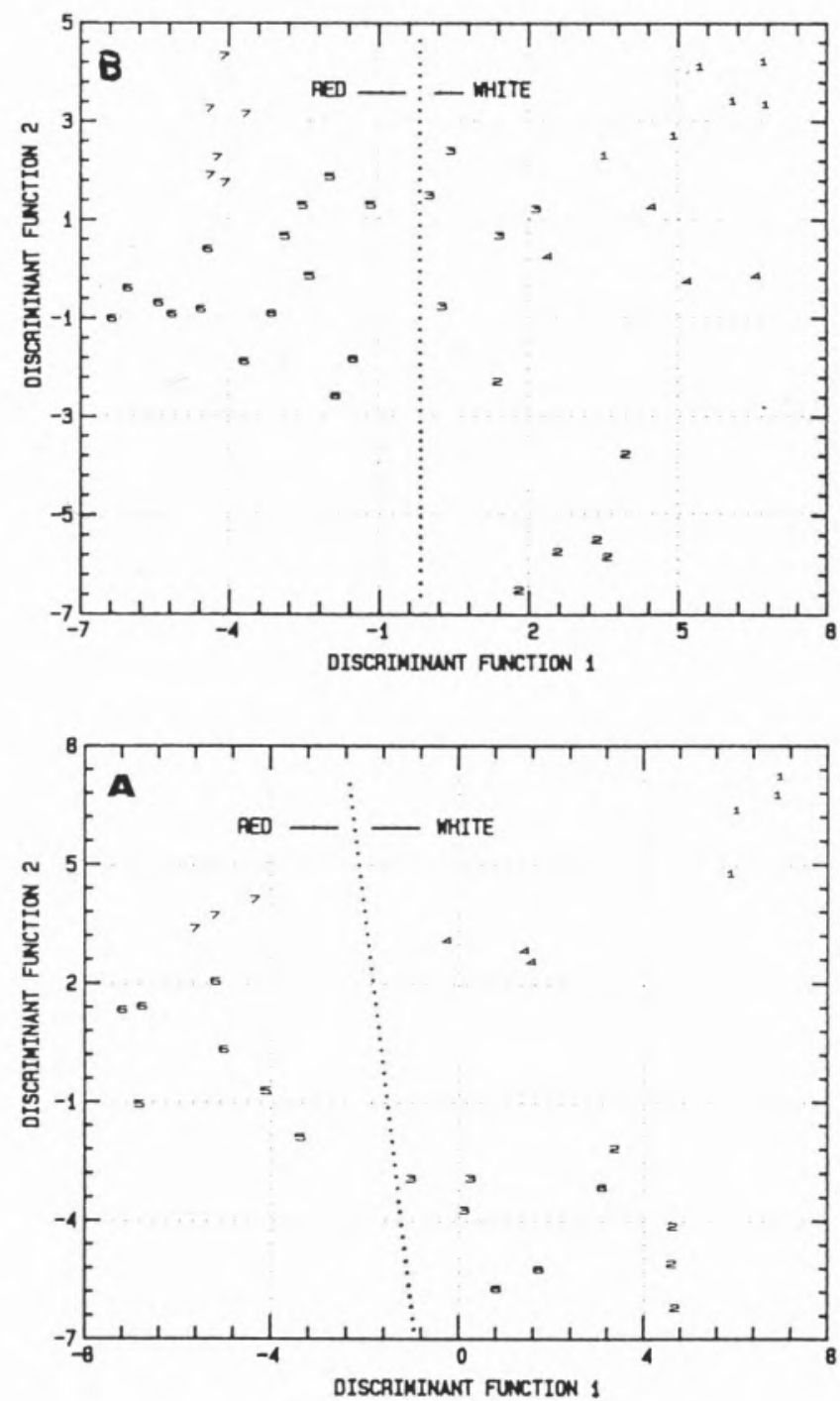

Figura 3

Análise Discriminante A-matriz total

B-"Jackniffing test series".

27 amostras variáveis usadas gli;

Val; Tre; Leu; Gaba; Pro; Met; Glx, Lys e Orn.
RED

Moreto. Aragonez Periquita Trincadeira
WHITE Roupeiro ROvelha Tamarez Manteudo

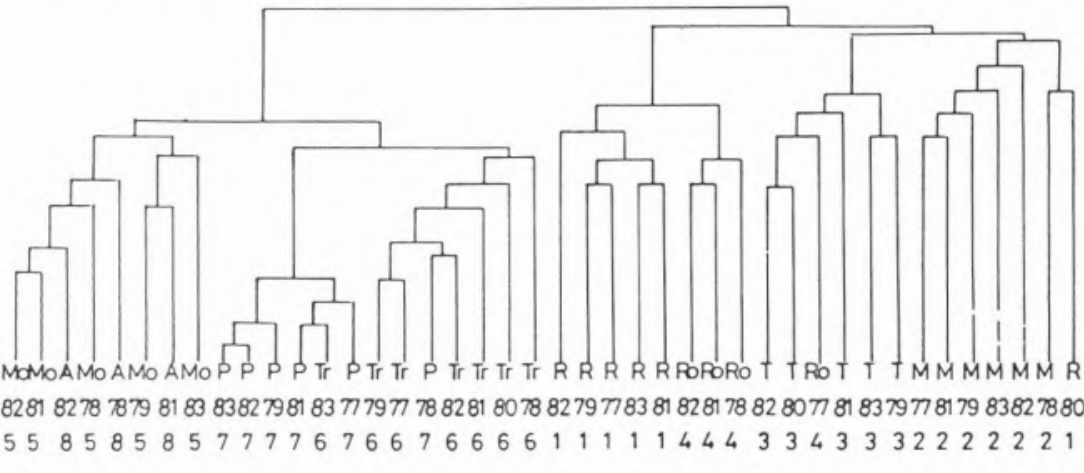

Já que a separação de Brancos e Tintos é visualmente possível experimentou-se a aplicação da técnica de análise discriminante aos vinhos brancos (Fig. 4A) e tintos separadamente (Fig. 4B). A separação varietal foi totalmente conseguida.

A aplicação da cromatografia quiral à análise dos aminoácidos livres dos vinhos da casta Roupeiro demonstrou-nos, não só a existência de aminoácidos D [11,12] nos vinhos bem como 0 facto de poderem os seus teores, depender de alguma forma da técnica de fermentação utilizada[12]. Na realidade a análise de agrupamento hierárquico, quando aplicada aos resultados obtidos, permite a distinção em duas populações que podem ser associadas quer ao tempo em garrafa [11] (mais que 10 anos em garrafa e menos que 10 anos em garrafa) quer ao método de fermentação[12] (fermentação tradicional de bica aberta nos vinhos até 1983 e fermentação no frio nos vinhos a partir de 1983) (Fig.5). 

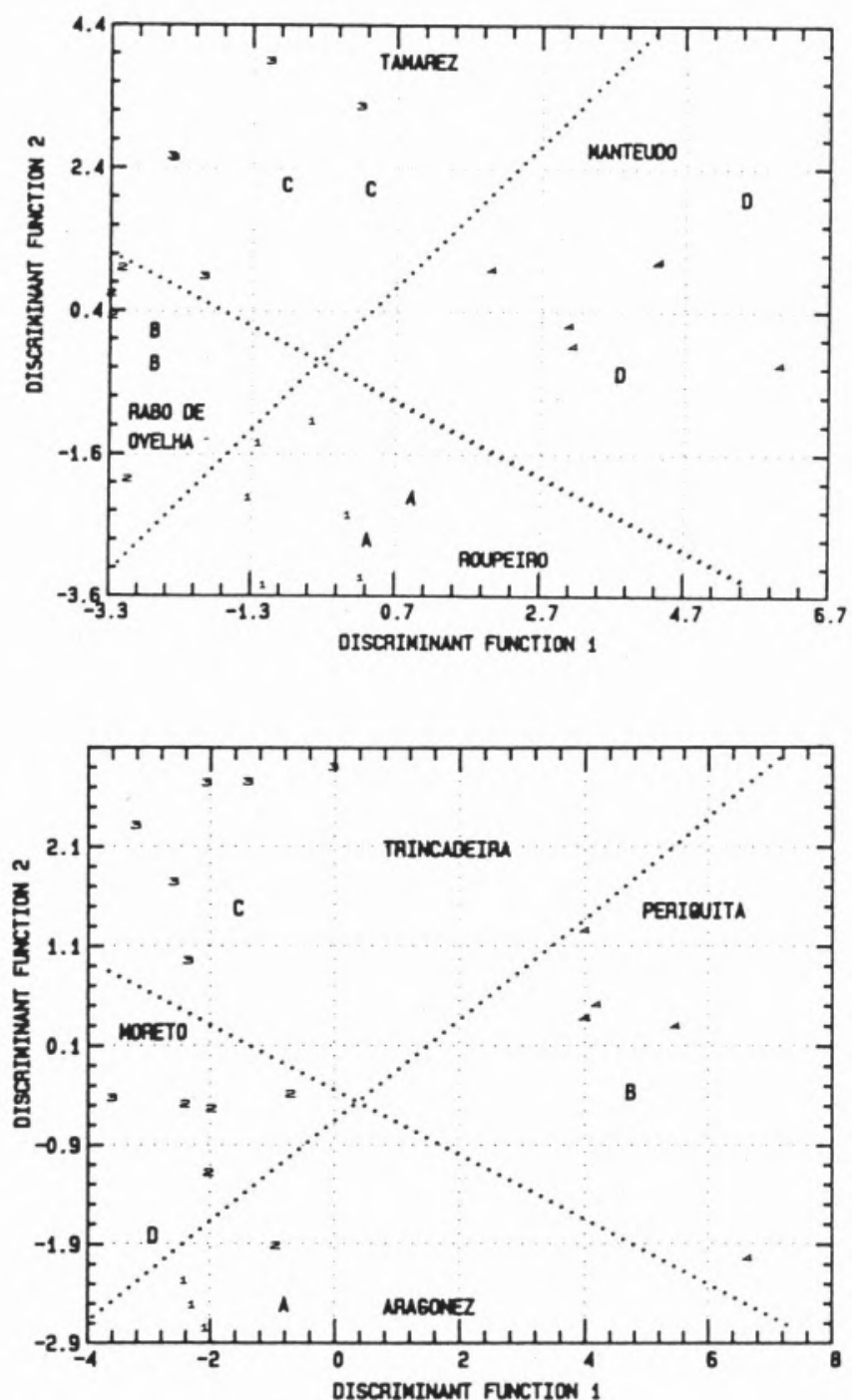

\section{AGRADECIMENTOS}

Figura 4 - Análise Discriminante: A-Vinhos Brancos: B- Vinhos Tintos

\section{CONCLUSÃO}

As técnicas de análise multivarietal aplicadas aos resultados dos aminoácidos livres de vinhos de castas alentejanas estudados durante um perído de sete anos, permitem extrair resultados susceptíveis de serem aplicados no reconhecimento de vinhos de regiões, ou na repressão de fraudes. 0 cálculo dos teores de aminoácidos $D$ presentes nos vinhos é um parâmetro cuja utilidade enológica deve ser explorada e desenvolvida. Os aminoácidos ( $D$ e $L$ ) livres provaram, pelas razões apontadas, ser um importante parâmetro a utilizar na caracterização enológica. coluna de Chirasil-Val.

\section{BIBLIOGRAFIA} Vinhos das Cooperativas Alentejanas. 1974. Unters-Forsch. 166 (1978) 298

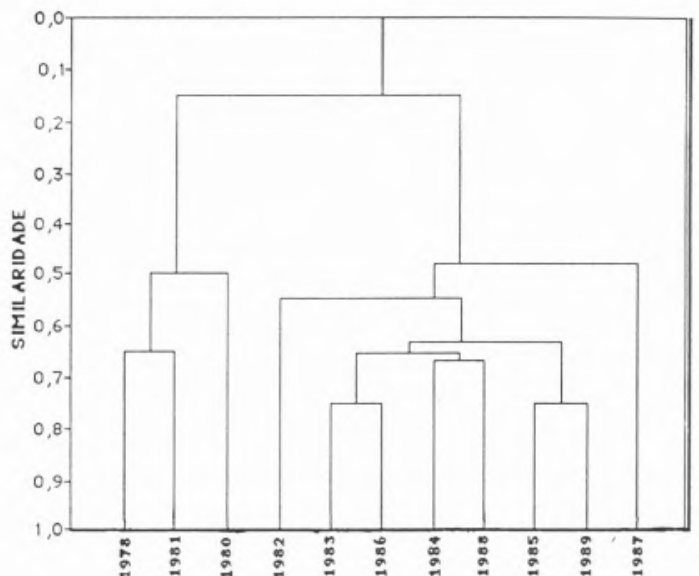

Figura 5 - Cluster Hierárquico dos aminoácidos D do vinho Roupeiro(ref. 11)

4. M. B. Lima, in Numerical Taxonomy ed. J. Felsenslein Springer verlag, Berlin-Heidelberg 5. W. Ooghe, H. Kastelijn, A. Waele, Ann. Fals Exp. Chim. 74 (1981) 381

6. W. O. Kwan, B. R. Kowalski, J Agric. Food Chem. 28 (1980) 356.

7. A. C. Noble, R. A. Fleth, R. R., Forrey J. Agric. Food Chem. 28 (1980) 346.

8. W. O. Kwan, B. R. Kowalski, J. Agric. Food Chem. 43 (1978) 1320.

9. A. D. Lachki, T. P. Tsiskarichvili, Vignes et Vin 211 (1972) 5.

10. A. M. P. Vasconcelos, Perfil de Aminoácidos Livres como Parâmetro Enológico para a Caracterização de Vinhos Elementares Alentejanos em Função da Casta de Origem - Dissertação de Doutoramento Évora, 1988. Chaves das Neves todo o apoio e orienta ção dado para a realização deste trabalho, ao Dr. J. Paulo da Costa Noronha, pelas análises dos aminoácidos $D$ no vinho Roupeiro e ao Prof. Doutor Hartmut Frank da Universidade de Tubinga pela cedência da

1. F. A. Colaço do Rosário, Caracterização dos Contribuição para o seu Estudo. E.R.A. - Évora

2. H. Siegmund, K. Bachman Z. Lebensm.

3. W. O. Kwan, B. R. Kowalski, R. K. Skogerboe, J. Agric. Food Chem. 27 (1979) 1321.
11. J. P. Noronha, Evolução da Pureza Enantiomérica dos Aminoácidos Livres em Vinhos Elementares da Casta Roupeiro, Provas de Aptidão Pedagógica e Científica Monte da Caparica, 1992

12. H. J. Chaves das Neves, A. M. P. Vasconcelos e M. L. Costa, in Chirality and Biological Activity 137-143, ed. Alan R. Liss, Inc, 1990.

13. A. M. P. Vasconcelos e H. J. Chaves das Neves, J. Agric Food Chem. 37 (1989) 934.

*Departamento de Química Universidade Nova de Lisboa 2825 Monte da Caparica 